\title{
Analysis of The Distribution Characteristics of Thoracolumbar Compression Fractures
}

\section{Ming-Xue Che}

Jilin University First Hospital

\section{Ming-Xi Liu}

Jilin University First Hospital

\section{Shao-Kun Zhang}

Jilin University First Hospital

\section{Zhen-Shan LV}

Jilin University First Hospital

Yuan-Zhe Jin

Jilin University First Hospital

Yao Zhao ( $\nabla$ zhaoyao1983@jlu.edu.cn )

Jilin University First Hospital https://orcid.org/0000-0002-1257-3098

\section{Research article}

Keywords: VCF, fractures, health

Posted Date: September 23rd, 2020

DOl: https://doi.org/10.21203/rs.3.rs-65447/v1

License: (c) (i) This work is licensed under a Creative Commons Attribution 4.0 International License.

Read Full License 


\section{Abstract}

Background:Vertebral compression fracture (VCF) is the most common osteoporotic fracture which significantly decreases patient's quality of life and high risk of subsequent osteoporotic fracture. VCFs also result in substantial financial burden on the public health system. Studying the characteristics of VCFs with analyzing the distributional differences by age and sex is meaningful for us to prevent and treat the VCFs.

Methods: We retrospectively reviewed the patients with thoracolumbar VCF from December 2012 to June 2018 in our department. A total of 675 cases met the study inclusion criteria for analysis. We divided the patients into four groups by age with every 10 years from 50 to 89 years old. Morbidity in each sex, the occurrence of single- or multisegment fractures and the distribution of fractures from T7 to L5 was calculated for every group. All the data was tested by SPSS.

Results: The highest proportion of male patients was in Group 4 (80-89 years old), and the lowest was in Group 2 (60-69 years old). The highest and lowest proportion of female patients was in Group 2 and Group 4, P value $<0.05$.

The highest proportion of multisegment fractures was in Group 3 (70-79 years old), and the lowest was in Group 1 (50-59 years old). The highest proportion of single-segment fractures was in Group 1, and the lowest was in Group 3, P > 0.05 .

Compared with the other vertebral fractures, L4 had $\mathrm{P}<0.05$; others were all $>0.05$.

Conclusions: As affected by individualized stress mechanisms of different vertebras and degree of osteoporosis, thoracolumbar VCFs have different characteristics that could assist physicians in carefully selecting treatment regimens to reduce pain and complications and improve the quality of life of patients.

\section{Introduction}

Vertebral compression fracture (VCF) is the most common type of osteoporotic fracture, with a prevalence equal to that of hip and distal radius fractures combined [1]. According to an epidemiological survey, there were 2.33 million cases of osteoporotic fractures in China in 2010, of which 1.11 million were vertebral fractures. It is predicted that by 2050 , there will be 5.99 million cases of osteoporotic fractures in China [2]. Previous studies showed that $25 \%$ of postmenopausal women older than 50 years and $40 \%$ of 80 -year-old women were affected by VCFs, indicating that the prevalence is both age- and sex-specific. Another study showed that $30-50 \%$ of adults older than 50 years suffered from VCFs, and VCF occurred every 2.2 seconds worldwide [3].

VCF is a serious type of osteoporotic fracture that is associated with a progressive loss of height, spinal kyphosis, pain, reduced mobility and independence, and psychological distress [4]. All the factors above result in a significant decrease in patient-reported health-related quality of life (HRQOL) and loss of 
quality-adjusted life years [5-7]. Moreover, a patient with VCF will likely experience another osteoporotic fracture in the spine or elsewhere. One in every 5 women with VCF will experience a second VCF within the following 12 months, and the risk of nonvertebral osteoporotic fractures, including those of the hip, increases 2 to 3 times [3]. Of great concern is that the long-term mortality in patients with a history of VCF is significantly higher than that in the general population and parallels mortality rates associated with osteoporotic hip fractures [3].

VCF is an expensive type of osteoporotic fracture, resulting in a substantial financial burden on the public health system. In the United States, the annual direct medical costs of osteoporotic fractures are estimated to be $\$ 12.2$ billion to $\$ 17.9$ billion [8]. The costs generated specifically by VCF have been appraised at more than $\$ 1.07$ billion [1]. In addition, the indirect costs due to patient and caregiver loss of productivity have been estimated at $\$ 6$ billion annually [9]. In China, the medical expenditure of osteoporotic fractures was 64.9 billion yuan in 2010 . It is predicted that by 2050 , medical expenditures will reach 174.5 billion yuan [2].

It is meaningful to effectively prevent the occurrence of VCF by studying its characteristics. Although it is a common consideration that the prevalence of VCF is both age- and sex-specific [10-11], these characteristics should be analyzed in depth.

\section{Material And Methods}

From December 2012 to June 2018, we studied 675 patients aged 50 to 89 years with thoracolumbar VCFs referred from the Spine Surgery Department of No. 1 Hospital of Jilin University. There were 150 male patients (22.22\%), 525 female patients $(72.81 \%), 415$ patients with single-segment fracture (72.81\%) and 155 patients with multisegment fracture (27.19\%).

The inclusion criteria were as follows: 1. patients with fracture in any segment from thoracic vertebra 7 to lumbar vertebra 5 ; 2 . patients aged 50 to 89 years; and 3 . patients in whom the VCF was caused by the patient themselves and who had normal cognitive ability. The exclusion criteria included the following: 1. patients with any violent fracture history or pathological fracture history (car accident, fall injury or tumor); 2. Patients with mental disorders, nervous system diseases or Alzheimer's disease; and 3. patients in whom osteoporosis was caused by endocrine diseases, such as diabetes or hyperparathyroidism.

We divided the patients into four groups by age. There were 107 patients (15.85\%) in Group 1 (5059 years old), 242 patients (35.85\%) in Group 2 (60-69 years old), 219 patients (32.44\%) in Group 3 (7079 years old), and 107 patients (15.85\%) in Group 4 (80-89 years old).

Morbidity in each sex, the occurrence of single- or multisegment fractures and the distribution of fractures from thoracic vertebra 7 to lumbar vertebra 5 was calculated for every group.

\section{Statistical analysis}


The statistical analyses was performed using SPSS software for Windows, version 20.0 (SPSS Inc, Chicago, IL). The count index is recorded as N (\%). The morbidity data of the 4 groups were compared using chi-square tests (the $\mathrm{P}$ value was calculated directly by the precise probability method when necessary). Statistical significance was established at $\mathrm{P}<.05$.

\section{Results}

\section{Comparison of proportions of vertebral compression fractures between sexes in different groups}

In all 675 patients, the proportions of males and females in the 4 groups were calculated and are shown in Table 1. The highest proportion of male patients was in Group 4 (36 cases, 33.64\%), and the lowest was in Group 2 (42 cases, 17.36\%). The highest proportion of female patients was in Group 2 (200 cases, $82.64 \%)$, and the lowest was in Group 4 (71 cases, $66.36 \%)$. The result of the statistical analysis had a P value $<.05$; therefore, there was a significant difference.

Table 1

The proportion of fractures by sex in each group

\begin{tabular}{|llllll|}
\hline Groups & Age & Male $(\%)$ & Female $(\%)$ & X2 & P \\
\hline Group 1 $(n=107)$ & $50-59$ years & $27(25.23)$ & $80(74.77)$ & 12.31 & 0.006 \\
\hline Group2 $(n=242)$ & $60-69$ years & $42(17.36)$ & $200(82.64)$ & & \\
\hline Group 3 $(n=219)$ & $70-79$ years & $45(20.55)$ & $174(79.45)$ & & \\
\hline Group 4 $(n=107)$ & $80-89$ years & $36(33.64)$ & $71(66.36)$ & & \\
\hline
\end{tabular}

Comparison of proportions of single-segment fractures and multisegment fractures in different groups

Among the 675 patients, there were 21 cases of multisegment fractures $(19.63 \%)$ and 86 cases of singlesegment fractures $(80.37 \%)$ in Group $1 ; 62$ cases of multisegment fractures $(25.62 \%)$ and 180 cases of single-segment fractures (74.38\%) in Group 2; 63 cases of multisegment fractures $(28.77 \%)$ and 156 cases of single-segment fractures $(71.23 \%)$ in Group 3; and 30 cases of multisegment fractures $(28.04 \%)$ and and 77 cases of single-segment fractures (71.96\%) in Group 4, as shown in Table 2. The proportion of multisegment fractures among the four groups was the highest in Group 3 (63 cases, accounting for $28.77 \%$ ) and the lowest in Group 1 (21 cases, 19.63\%). The highest proportion of single-segment fractures among the four groups was in Group 1 (86 cases, 80.37\%), and the lowest was in Group 3 (156 cases, $71.23 \%$ ). The result of statistical analysis indicated $P>0.05$; therefore, there was no significant difference. 
Table 2

The proportions of single-segment fractures and multisegment fractures in the different groups

\begin{tabular}{|c|c|c|c|c|c|}
\hline Groups & $\begin{array}{l}\text { Age } \\
\text { (years) }\end{array}$ & $\begin{array}{l}\text { Multisegment Fractures } \\
(\%)\end{array}$ & $\begin{array}{l}\text { Single-segment Fracture } \\
(\%)\end{array}$ & $x^{2}$ & $P$ \\
\hline $\begin{array}{l}\text { Group } 1(\mathrm{n}= \\
107)\end{array}$ & $50-59$ & $21(19.63)$ & $86(80.37)$ & 3.372 & 0.338 \\
\hline $\begin{array}{l}\text { Group2 }(n= \\
242)\end{array}$ & $60-69$ & $62(25.62)$ & $180(74.38)$ & & \\
\hline $\begin{array}{l}\text { Group } 3(\mathrm{n}= \\
219)\end{array}$ & $70-79$ & $63(28.77)$ & $156(71.23)$ & & \\
\hline $\begin{array}{l}\text { Group } 4(\mathrm{n}= \\
107)\end{array}$ & $80-89$ & $30(28.04)$ & $77(71.96)$ & & \\
\hline
\end{tabular}

\section{Comparison of the proportionof vertebral fractures in different segments in different groups}

There were 977 fractured vertebrae in 675 patients who were divided into 11 groups by segment, from thoracic 7 to lumbar 5 . Comparisons were conducted by age groups as mentioned above and are shown in Table 3. The results of the comparisons, including the $\chi 2$ values and $P$ values, are also shown in Table 3. Compared with the other vertebral fractures, the $P$ values of $L 4$ were $<.05$ in all 4 groups, with significant differences; the other $P$ values were all $>.05$, with no significant differences found.

Table 3

The proportions (\%) of vertebral fractures in different segments in the different groups (977 vertebral fractures in 675 patients)

\begin{tabular}{|l|l|l|l|l|l|l|}
\hline Groups Group 1 $(\mathrm{n}=\mathbf{1 0 7})$ & Group2 $(\mathrm{n}=\mathbf{2 4 2})$ & Group 3 $(\mathrm{n}=\mathbf{2 1 9})$ & Group 4 $(\mathrm{n}=\mathbf{1 0 7})$ & Statistical Index \\
\hline Age & $50-59$ years & $60-69$ years & $70-79$ years & $80-89$ years & X2 & P \\
\hline T7 & $2(1.87)$ & $12(4.96)$ & $7(3.2)$ & $2(1.87)$ & & 0.431 \\
\hline T8 & $6(5.61)$ & $15(6.2)$ & $18(8.22)$ & $6(5.61)$ & 1.319 & 0.725 \\
\hline T9 & $2(1.87)$ & $9(3.72)$ & $8(3.65)$ & $2(1.87)$ & & 0.734 \\
\hline T10 & $8(7.48)$ & $11(4.55)$ & $14(6.39)$ & $5(4.67)$ & 1.647 & 0.649 \\
\hline T11 & $7(6.54)$ & $37(15.29)$ & $34(15.53)$ & $13(12.15)$ & 6.043 & 0.11 \\
\hline T12 & $34(31.78)$ & $71(29.34)$ & $68(31.05)$ & $29(27.1)$ & 0.753 & 0.861 \\
\hline L1 & $37(34.58)$ & $99(40.91)$ & $81(36.99)$ & $31(28.97)$ & 4.808 & 0.186 \\
\hline L2 & $28(26.17)$ & $41(16.94)$ & $36(16.44)$ & $23(21.5)$ & 5.613 & 0.132 \\
\hline L3 & $10(9.35)$ & $27(11.16)$ & $28(12.79)$ & $17(15.89)$ & 2.496 & 0.476 \\
\hline L4 & $8(7.48)$ & $20(8.26)$ & $29(13.24)$ & $18(16.82)$ & 7.957 & 0.047 \\
\hline L5 & $1(0.93)$ & $9(3.72)$ & $10(4.57)$ & $5(4.67)$ & 7 & 0.35 \\
\hline
\end{tabular}

\section{Discussion}

Osteoporosis is a bone disease with increasing prevalence with age [12]. The bone mass of humans, which is related to age, increases in childhood and adolescents but begins to slowly decrease at a rate of approximately $0.5 \%$ per year after reaching its peak in adulthood [13]. Bone mineral density (BMD) is an intrinsic factor associated with brittle fracture of the spine, and osteoporosis (low BMD) is the most serious risk factor [14]. In the population over the age of 50, VCFs caused by osteoporosis, minor trauma or no obvious trauma are relatively common, causing serious public health problems due to disability, decreased quality of life and increased mortality [15]. 
In our study, nearly all the cases occurred in the 60 to 69 years group and the 70 to 79 years group. The number of cases were obviously higher than those in the 50 to 59 years group or the 80 to 89 years group. We believe that the loss of bone mass is not great enough to confer an extreme risk of VCF until the age of 60 . However, the low rate of VCF in the 80 to 89 years group should be explained. The main reason for this phenomenon is that the population aged 80 to 89 years is smaller than the populations of the other age groups. According to the 2010 population census of China from the National Bureau of Statistics, the population of individuals aged 80 to 89 years was 19 million, whereas that of individuals aged 60 to 69 years was almost 100 million [16]. Although the probability of VCF is higher in elderly individuals, the age group is the determining factor. Moreover, elderly individuals lose the ability and willingness to participate in social activities with increasing age, which means a relatively decreased risk of developing fracture [17]. It has been estimated that more than $70 \%$ of VCFs are silent [18]. Sometimes the symptoms are too minor to be noticed, and elderly individuals do not realize that they have a VCF until they undergo radiography for another condition or experience a secondary osteoporotic fracture. In addition, the lack of knowledge about osteoporotic fractures in elderly individuals and their families is an obstacle to being addressed.

In our study, we found that the proportion of VCF in female patients was higher than that in male patients aged 50-89 years. With increasing age, the proportion of VCF decreased in female patients and increased in male patients, with $P$ values $<0.05$, indicating a significant difference. The proportion of vertebral fractures in female patients aged 60-69 years was the highest (82.64\%), and there was a significant decrease $(66.36 \%)$ in the $80-89$ years age group. The risk of fracture increases because the activity of osteoclasts increases, which can lead to osteoporosis because estrogen levels decline rapidly during late menopause [19]. The peak bone mass in males is greater than that in females, and the occurrence of bone loss occurs later in life. In addition, the decline in androgens is gradual, so the amount and rate of bone loss in males is less than that in females. In this study, VCFs in females were found to predominate in the 60-69 years age group, while the proportion in the 80-89 years age group showed a significant decrease, which was statistically significant.

The results of this study showed that the $P$ values between single-segment fractures and multisegment fractures in all age groups were $>0.05$ and were not statistically significant. Moreover, the proportions of multisegment VCFs did not increase significantly. Therefore, this study shows that patients with singlesegment fractures can be stabilized through prevention or treatment and may not develop multisegment fractures.

This study shows a trend that stress diffuses from T12, with stress gradually concentrating in L1, L2, L3, and $L 4$ according to the comparison of the vertebral segment with fractures. However, only the $P$ values of $L 4$ vertebral fractures in each age group were significant, with values $<0.05(0.047)$. When a patient falls backward, the energy of compression diffuses from his/her lower lumbar vertebrae up to thoracic vertebrae. The vertebra, which absorbs most of the energy, fractures. Therefore, the occurrence of VCF in $L 4$ increases with age, indicating that the $L 4$ vertebra is most affected by deterioration due to 
osteoporosis. We can regard VCF in L4 as a threshold of the degree of osteoporosis in a sense and as an indicator of the probability of suffering another osteoporotic fracture, including VCF.

In 2001, the United States National Institutes of Health (NIH) stated that osteoporosis is a bone disease causing a decrease in bone strength, resulting in an increase in fracture risk. Bone strength comprises two essential factors: bone mass and bone quality. The auxiliary method of quantitative CT (QCT) measurement of BMD combined with the finite element model to analyze bone strength may be more effective than a single method in preventing and treating osteoporotic VCF.

Twenty-one percent of women with osteoporosis experience one or more osteoporotic fractures, and they can suffer an additional fracture within one year after vertebroplasty [20]. Physicians who perform vertebroplasty should inform patients with osteoporosis that they may experience fracture again within a year. Our study showed that the proportion of multisegment fractures was $20.68 \%$, which is in accordance with the data above. The $P$ values of the comparisons of the proportions of single-segment fractures and multisegment fracture in each age group were $>0.05$, with no statistical significance. However, we found that the rate of multisegment fractures increased with age, as shown in Table 2. Lindsay et al. [21] found that once osteoporotic VCF occurs, there is a high risk of additional fracture in the future. The main risk factor is underlying osteoporosis. The rates of single and multiple VCFs increase with age, and the osteoporosis condition deteriorates. Considering the understanding of the progress trend of osteoporotic fractures, it is possible to prevent the occurrence of VCF.

Since this study was limited to inpatients in the Department of Spinal Surgery in the First Hospital of Jilin University, there may be bias in the structural composition of the study population; therefore, the sample size should be increased in a future in-depth study. In conclusion, there are certain rules to follow for VCFs in patients over the age of 50 . Further research and knowledge can improve the ability to prevent and treat VCFs.

\section{Conclusions}

As affected by individualized stress mechanisms of different vertebras and degree of osteoporosis, thoracolumbar VCFs have different characteristics that could assist physicians in carefully selecting treatment regimens to reduce pain and complications and improve the quality of life of patients.

\section{Abbreviations}

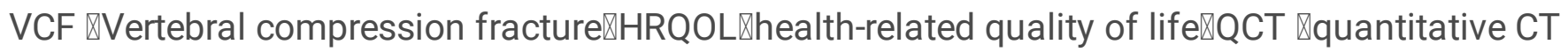

\section{Declarations}

\section{Ethics approval and consent to participate}


The study protocol was approved by the ethics committee of The First Hospital of Jilin University. Because of the retrospective nature of the study, patient consent for inclusion was waived by the committee.

\section{Consent for publication}

Applicable.

\section{Competing interest}

The authors have no conflict of interest to disclose.

\section{Availability of data and materials}

All data, models, and code generated or used during the study appear in the submitted article.

\section{Funding}

No funding was received for this study.

\section{Authors' contributions}

Ming-Xue Che collected the data and drafted the manuscript. Ming-Xi Liu evaluated the radiographic findings. Zhen-Shan Lv and Yuan-Zhe Jin mainly calculated sample size, and Shao-Kun Zhang supervised it. Yao-Zhao designed the study. All authors had complete access to all data used in this study and take responsibility for its accuracy. All authors have read and approved the final manuscript.

\section{Acknowledgements}

Not applicable.

\section{References}

1. Burge R, Dawson-Hughes B, Solomon DH, Wong JB, King A, Tosteson A. Incidence and economic burden of osteoporosis-related fractures in the United States, 2005-2025. J Bone Miner Res. 2007;22:465-75. https://doi.org/10.1359/jbmr.061113.

2. Si L, Winzenberg TM, Jiang Q, Chen M, Palmer AJ. Projection of osteoporosis-related fractures and costs in China: 2010-2050. Osteoporos Int. 2015;26:1929-37. https://doi.org/10.1007/s00198-0153093-2.

3. Bouxsein ML, Genant HK. International osteoporosis foundation. The Breaking Spine, http://www.iofbonehealth.org/breaking-spine-report-2010; 2010 [accessed 22 February 2015].

4. Varacallo MA, Fox EJ. Osteoporosis and its complications. Med Clin N Am. 2014;98:817-31. https://doi.org/10.1016/j.mcna.2014.03.007. xii-xiii. 
5. Oleksik A, Lips P, Dawson A, Minshall ME, Shen W, Cooper C. Health-related quality of life in postmenopausal women with low BMD with or without prevalent vertebral fractures. J Bone Miner Res. 2000;15:1384-92. https://doi.org/10.1359/jbmr.2000.15.7.1384.

6. Tosteson AN, Gabriel SE, Grove MR, Moncur MM, Kneeland TS, Melton LJ 3. Impact of hip and vertebral fractures on quality-adjusted life years. Osteoporos Int. 2001;12:1042-9. https://doi.org/10.1007/s001980170015. rd. .

7. Oleksik AM, Ewing S, Shen W, Van Schoor NM, Lips P. Impact of incident vertebral fractures on health related quality of life (HRQOL) in postmenopausal women with prevalent vertebral fractures. Osteoporos Int. 2005;16:861-70. https://doi.org/10.1007/s00198-004-1774-3.

8. Tosteson AN, Hammond CS. Quality-of-life assessment in osteoporosis: health-status and preference-based measures. Pharmacoeconomics. 2002;20:289-303. https://doi.org/10.2165/00019053-200220050-00001.

9. World Health Organization Collaborating. Center L. Belgium on behalf of the IOF Committee of Scientific Advisors, International Osteoporosis Foundation. Invest in Your Bones. Osteoporosis in the workplace: the social, economic and human costs of osteoporosis on employees, employers and governments, http://www.iofbonehealth.org/osteoporosis-workplace-report-2002; 2002 [accessed February 22 2015].

10. Ho-Pham LT, Mai LD, Pham HN, Nguyen ND, Nguyen TV. Reference ranges for vertebral heights and prevalence of asymptomatic (undiagnosed) vertebral fracture in Vietnamese men and women. Arch Osteoporos. 2012;7:257-66. https://doi.org/10.1007/s11657-012-0106-z.

11. Lau EM, Chan HH, Woo J, Lin F, Black D, Nevitt M, et al. Normal ranges for vertebral height ratios and prevalence of vertebral fracture in Hong Kong Chinese: a comparison with American Caucasians. J Bone Miner Res. 1996;11:1364-8. https://doi.org/10.1002/jbmr.5650110922.

12. Amin S, Achenbach SJ, Atkinson EJ, Khosla S, Melton LJ 3. Trends in fracture incidence: a population-based study over 20 years. J Bone Miner Res. 2014;29:581-9. https://doi.org/10.1002/jbmr.2072. rd. .

13. Ferrari SL. Osteoporosis: a complex disorder of aging with multiple genetic and. environmental determinants. World Rev Nutr Diet. 2005;95:35-51. doi:10.1159/000088271.

14. Broe KE, Hannan MT, Kiely DK, Cali CM, Cupples LA, Kiel DP. Predicting fractures using bone mineral density: a prospective study of long-term care residents. Osteoporos Int. 2000;11:765-71. https://doi.org/10.1007/s001980070055.

15. Rachner TD, Khosla S, Hofbauer LC. Osteoporosis: now and the future. Lancet. 2011;377:1276-87. https://doi.org/10.1016/s0140-6736(10)62349-5.

16. National Bureau of Statistics of the People's Republic of China. The sixth national. census main data bulletin. 2011. http://www.gov.cn/test/2012-04/20/content_2118413.htm.

17. Cummings SR, Melton LJ. Epidemiology and outcomes of osteoporotic fractures. Lancet. 2002;359(9319):1761-7. doi:10.1016/S0140-6736(02)08657-9. 
18. Fink HA, Milavetz DL, Palermo L, Nevitt MC, Cauley JA, Genant HK, et al. What proportion of incident radiographic vertebral deformities is clinically diagnosed and vice versa? J Bone Miner Res. 2005;20:1216-22. https://doi.org/10.1359/jbmr.050314.

19. Blake GM, Fogelman I. The role of DXA bone density scans in the diagnosis and. treatment of osteoporosis. Postgrad Med J. 2007;83(982):509-17. doi:10.1136/pgmj.2007.057505.

20. Syed MI, Patel NA, Jan S, Harron MS, Morar K, Shaikh A. New symptomatic vertebral compression fractures within a year following vertebroplasty in osteoporotic women. AJNR Am J Neuroradiol. 2005;26:1601-4.

21. Lindsay R, Silverman SL, Cooper C, Hanley DA, Barton I, Broy SB, et al. Risk of new vertebral fracture in the year following a fracture. JAMA. 2001;285:320-3. https://doi.org/10.1001/jama.285.3.320. 